\title{
From Art to Cure: The Three Stages of Theoretical Development of Ancient Chinese Painting from Pre-Qin to Qing Dynasty
}

\author{
Na Luo \\ School of English for International Business, Guangdong University of Foreign Studies, Guangzhou, China \\ Email address: \\ ronagdufs2010@163.com

\section{To cite this article:} \\ Na Luo. From Art to Cure: The Three Stages of Theoretical Development of Ancient Chinese Painting from Pre-Qin to Qing Dynasty. \\ International Journal of Literature and Arts. Special Issue: Humanity and Science: China's Intercultural Communication with the Outside \\ World in the New Era. Vol. 8, No. 2, 2020, pp. 39-45. doi: 10.11648/j.ijla.20200802.12
}

Received: February 27, 2020; Accepted: March 11, 2020; Published: March 31, 2020

\begin{abstract}
Ancient Chinese paintings, compared with traditional Western oil paintings that featured realistic depiction, seem mysterious enough to go beyond comprehension to Westerners. It could be traced back to one of the fundamental divergences in history when ancient Chinese painters and critics took a path not taken by their Western counterparts at the theoretical development crossroad over a thousand years ago: the former started to strive not for realistic drawing skills improvement but for the spiritual connection between the object and the painting. In the theoretical development of ancient Chinese painting, it marks the critical turning point from the first imitation stage of pursuing xingsi (formal likeness) to the intermediate second stage of seeking shensi (spiritual resemblance); and eventually in its third stage, painting became a constitutional part of Chinese ancients' lifestyle when it switched for a breakthrough from figure painting to landscape painting that laid more emphasis on subjective xieyi (intent-expression) which, by taking on a form of catharsis, played an extremely important role in the life of ancient painters and painting-lovers. That is when painting was endowed with a new function of more realistic importance: it was viewed by ancient Chinese as something more than art but therapeutic as a cure to relieve their miseries and pains by way of self-expression or aesthetic resonances. Imbibing the Taoist philosophy renowned for its profound effect on health preserving, specifically its aesthetic and contemplative attitude towards life advocated by Zhuangzi, these ancient Chinese painters and their audience sought xieyi and all-pervading oneness by blending themselves with the universe to find their own spiritual healing power.
\end{abstract}

Keywords: Ancient Chinese Painting, Painting Theory, Intent Expression, Taoist Philosophy

\section{Introduction}

Chinese painting with its theory was first known to more Westerners in early $20^{\text {th }}$ century when Kakuzo Okakura published The Ideals of the Eastern in which he translated some theoretical concepts proposed by a Chinese painter and painting critic named Xie He (479-502). With the popularity of this book and later introductions by sinologists as Herbert Allen Giles and Raphael Petrucci etc., Chinese painting and its theory since then have fascinated Western artists, as Poskaite commented, [1] "Painting, and especially landscape painting is maybe the most meaningful and impressive visual embodiment of the process of transformation, or generation and regeneration, especially if we have in mind a common idea about the origins of painting from Yijing (The Book of Change) and trigrams as symbols and images of cosmic change, which have prevailed in Chinese painting theory since its beginning".

In its over two-thousand-year evolution, ancient Chinese painting theory has developed distinct phases based on the subject-object relation in painting as well as its function: from the very primary phase of xingsi (form likeness), to shensi (spiritual resemblance) as a connecting link, and ultimately to a subject-object integration and perfection by xieyi (intent expression). Examined in the macro socio-historical and cultural context of ancient China, ancient Chinese painting and its theory, at the crossroad when artists worldwide started to pursue more than rigid imitation, actually stepped on a road quite different from which was taken by European oil painters and critics. "The Chinese were the first people who did not think of the making of pictures as a rather menial task, but who 
placed the painter on the same level as the inspired poet." [2] Meanwhile, the application of ancient Chinese philosophy to painting was quite natural and particularly fruitful. Paintings thus created have aesthetically enriched people's lives with various styles, and eventually become an essential part of their lifestyle as spiritual sustenance and panacea.

Dividing the theoretical development of painting into three phases in terms of its functional subject-object relation helps to draw a clear picture of its history. Scholars have been long studying chuanshen (conveying the spirit), focusing on how the spirit of things was conveyed but sparing little attention to expression of a painter's intent, [3] and still less to imitation of physical objects. As spiritual resemblance was intended to solve the fundamental issue of capturing the essence of the object, it was once considered by ancient Chinese painters as to take the central position in the theoretical development. Nevertheless, paintings created at the very first beginning of human history were mostly imitations of things and they served to lay the foundation, while those meant to express personal intent have been proved to have played far more important roles alongside aesthetic effect. Zhang Yanyuan (815-907) commented on the act of painting of Gu Kaizhi (348-409).

Object and self forgotten, he departs from forms and leaves knowledge behind. When the body can truly be made to be like dry wood, and the mind can truly be made to be like dead ashes, is this not to have attained mysterious principles? It is what can be called the true way (Tao) of painting. [4]

Here upon Gu's producing his painting, the impact of classical Taoist philosophy, especially by Zhuangzi, is easily discernable. "Chinese painters did not try to acquire a rational comprehension of the divine world by means of mathematics and geometry, and did not present nature in this way... To them, the world was ... rather the place in which they lived." [5] Such Views and theories originating from Taoism and developed in Chinese painting tradition are "not only aesthetic but also therapeutic", [1] due to the fact that producing and contemplating upon Chinese painting, especially landscape painting, have been considered by some Chinese, and later by many Westerners as a way to improve one's health, to better understand oneself, and to lead a sounder lifestyle by maintaining a more balanced relationship with nature. That is, ancient Chinese painting and its theory, after pursuing formal likeness and spiritual resemblance as art, started to be endowed with a curing power at its third stage by engaging more subjective elements in artistic creation and appreciation.

\section{Images of the Eight Trigrams as the Initial Inspiration}

The creation of aesthetic images can be traced back to the invention of guaxiang (trigrams). Zhouyi (The Zhou Book of Change) was originally written on the basis of ancient Chinese people's observation of "the celestial phenomena" and their examination of "geographic features" by "select [ing] symbols close from human body and far away from various objects" and by "comparing them (esoteric principles under heaven) to concrete states and appearances, and symbolizing them with appropriate objects and meanings." [6] Images of the eight trigrams were invented as a result of extraction of objects full of vital force for the purpose of taking it as symbols of the brilliant and miraculous virtue of nature and as analogies to states of all things of creation under heaven.

The artistic production of xiang (image) in painting is quite similar to the creation of trigrams, as "hsiang (or xiang) as a noun must have signified visible manifestation of phenomena which could be either abstract or material."[7] However, the way of "observing" and "contemplating" in art creation differs from that in trigrams that developed from abstraction and cognition. A painter does not simply watch his object with instinctive feelings, nor look on everything with himself kept at a distance, but instead, he is moved and absorbed, using his own life to feel another life.

In terms of theoretical development, Chinese philosophy of art or aesthetic appeared for music and for literature much earlier than it did for painting; [7] the earliest sources of the latter are more concerned with practical issues. Kaogong $\mathrm{Ji}$ (Book of Diverse Crafts) in Zhouli (Rites of the Zhou) classified painters as skillful craftsmen differentiated from those who specialized in creation. [8] That is probably because painters at that time were mere artisans whose works were hardly considered artworks. Zhuangzi (as a book written before $221 \mathrm{BC}$ ) also mentioned an anecdote about painting.

When Duke Yuan of Song wanted to have a picture painted, all the court painters gathered in his presence. After they received the instructions and bowed to the duke, some of them stood around, licking their brushes and mixing their ink. Half of them were waiting outside. One of them, who arrived late, came in leisurely steps. After he received the instructions and bowed to the duke, he did not wait but went straight to his quarters. When the duke sent someone to see what he was doing there, the painter was found undressed and seated on the mat. Duke Yuan said, "He will do. He is a true artist." [9]

It's barely about painting theory, nor anything about images in painting, however, the author seemed to illustrate that an artist is not subject to mundane rituals but follows what is natural. The beginning of this approach in Chinese theory of art, which later became one of the main specific features of Chinese painting theory, and which regards shenqi (spiritual quality) as the highest aim of art, can actually be traced back to prince Liu An (179BC-122BC) in the Western Han Dynasty (206 BC-24 $\mathrm{AD})$. Yet, the idea of searching for the spirit did not come straight from preserved ancient essays on painter's social status or act of painting, but evolved from a primitive pursuit of imitating the sensuous colors and shapes of physical things.

\section{The Three Stages of Theoretical Development of Ancient Chinese Painting}

\subsection{The First Stage: Form Likeness Through Imitation}

The earliest standard for quality assessment of a painting, 
which largely stressed likeness between the painted and the painting in pursuit of a functional realism, is undoubtedly rooted in Zhouyi (The Zhou Book of Change), "When the sages discovered the esoteric principles under heaven, they compared them to concrete states and appearances, symbolized them with appropriate objects and meanings, and thus called them images." [6] To define painting by the concept of image reveals how much people in pre-Qin period knew about the art of painting. Hanfeizi (280 BC-233 BC) of pre-Qin period believed that dogs or horses were hard to paint, for they were so common to be seen by everyone that it's quite challenging to paint them with likeness and vividness; in contrast, ghosts and goblins were much easier, for nobody actually knew what they looked like and a painter was thus endowed with absolute freedom in his creation. [8] It seems that pre-Qin painters have a unanimous preference for ghosts and goblins over dogs or horses.

How pre-Qin people evaluated the function and advantage of painting also reveals how they defined painting. Zhang Yanyuan (815-907) said, "Ideas need to spread far and wide, and that's how books come into being; images need to be seen, and that's why paintings come into play." [10] More specifically, records of historical figures could tell their stories but couldn't present their facial or physical features, rhyme-prose and poetry could extol their beauty and nobleness but couldn't present their actual image; only a painting can simultaneously satisfy a reader and viewer.

Form likeness through imitation has played a positive role in highlighting the irreplaceably distinctive characteristics of painting compared with other art forms albeit its overemphasis upon exterior features of shape, size and color etc; however, as art is gradually supposed to go beyond reality, pursuit of form likeness was often played down by Chinese ancients. As time went by, it was somehow marginalized and only embraced by literati who theoretically knew little about painting. For hundreds of years, it has been criticized as not able to reveal the essence or true value of painting. And what's even worse, a painter's hardheaded pursuit of "form likeness" imposes restrictions on presenting inner vitality of object, contributing to failure in achieving "real likeness". Su Shi (1037-1101), a renowned poet, painter, calligrapher of the Northern Song dynasty (960-1127), castigated the pursuit of form likeness in painting as "knowledge of a naïve child". [11] Artists believed that "Sages, possessing the Tao, respond to things. The virtuous, purifying their thoughts, savor images. As for landscape, it has physical existence, yet tends toward the spiritual." [7] In the sense of theoretical development of painting rather than particular historical period, that is when appeared the crossroad where painters and critics started looking for better ways to represent the physical world. But ancient Westerners and their Chinese counterparts headed for entirely different directions: while "numbers, measures, and symmetry are all codes of God who teaches European painters the essence of painting, the root of Art," and "Europeans could see in an object the geometrical forms that were taken as a more essential dimension," Chinese painters "even deliberately avoided the help of drafting instruments and resisted the temptation to render the shapes in their painting geometrically," and "the communication between audience and work was realized by means of the common practice of character-writing, familiar since childhood." [5]

\subsection{The Second Stage: Spiritual Resemblance Through Imagination}

From the oldest sources on ancient Chinese painting, it is possible to claim that Chinese theory of painting and art as a whole has taken its own route. Problems that showed great importance to European intellectuals attracted them one way, while those that captured ancient Chinese philosophers' attention allured them to concentrate on entirely different concerns. "The similarity of the shape in ancient Chinese art theory, or at least part of the ancient Chinese art theorists, was not the highest aim of painting.... There is a hidden possibility that it can completely abandon the outer shape in painting." [12] In the story told by Zhuangzi, shenqi (spiritual quality) of the "true artist" praised by Duke Yuan of Song was exemplified in the philosophy of a Han prince and philosopher Liu An (179BC-122BC), the author of Huainanzi. He seemed not contented with formal imitation, but instead considered shen (the spirit) as what should be sought in art.

When somebody paints the beautiful face of $\mathrm{Xi} \mathrm{Shi}^{1}$ in a way that does not convey pleasant feelings, or paints the glaring eyes of warrior Meng $\mathrm{Ben}^{2}$ in a way that does not scare people, the vital temperament of figures was lost in painting. [13]

Liu's comments indicate that he saw beyond the rigid imitation and started to pursue subtleties in painting through more vivid imagination and tacit understanding. The supposedly conveyed "pleasant feelings" from a beautiful face and the expected frightening effect of a warrior's "glaring eyes" represent their respective typical idiosyncrasies that would convey shen (the spirit) of the figure. And it takes an incisive and imaginative painter to capture the object's real spirit.

Gu Kaizhi (348-409) was generally regarded as the theoretician who proposed the term "chuanshen" (conveying the spirit) that could mean that "while painting figures the most important is to express their inner feelings, but also the transmitting of the ideas, spirit, or the inspiration in painting." [12] This Eastern Jin (317-420) talented painter lived in a politically unstable period when social turbulence caused decease of traditional values of Confucianism, prompted great development of Buddhism and witnessed fruitful intellectual movement. Both Taoism and Buddhism and their mutual interaction on many different levels had an essential influence on Chinese painting.

"On a higher level, however, the Taoists were the intellectual avant-garde. The reaction against Confucianism

\footnotetext{
$1 \mathrm{Xi}$ Shi (of the Spring and Autum Period) was the first of the four best known beauties in ancient China.

2 Meng Ben (of the Warring States Period) was a fierce warrior who had a reputation for his great physical strength as to easily lift an ancient bronze cooking vessel.
} 
had produced a 'thaw' in the rigidly traditional view of art and literature, and now the imagination took fight once more in poetry and literature more inspired than any since the elegies of Chu. ...This was not merely escape from political and social chaos; it was escape into the world of the imagination." [14]

Yet, there seems no clear-cut boundary between the termination of pursuing form likeness and the emergence of seeking spiritual resemblance in Chinese art philosophy; instead, there was a considerable length of time when there was a harmonious coexistence. Liu Xie (465-520), the author of The Literary Mind and the Carving of Dragons, claimed, "They consider the highest excellence to be getting the form of things, and the greatest accomplishment to reside in close adherence (to the original)." [15] Around two centuries later, Wang Changling (698-757), a Tang (618-907) poet, defined "form likeness" as what can be acquired when "(the artist's) heart receives and the spirit knows it, imagining himself in live situation to let it recur in his heart and poise in his palm quite ready for art creation, and then through meditation, he has a tacit and thorough understanding of the image and context." [16] Works created in this way were deemed to embrace absolute form likeness, for which a painter needed to feel his object wholeheartedly, pursue a spiritual integration, and have an understanding beyond the physical object after mental reflection. But curiously enough, Wang's prescription, albeit its lack of operable procedural details, seems quite enlightening to painters who aimed for spiritual resemblance.

Together with inspirations from Buddhism and Taoist philosophy, it was specifically figure painting with its technical development that nourished the theory of chuanshen (conveying the spirit) in ancient Chinese painting. Gu was concerned with reaching the characteristic features of his object of painting, the most famous of which were historical or imaginary figures (eg. court ladies and Goddess of the Luo River). He said that paintings have to express shenqi (spiritual quality), and claimed that shen (the spirit) should be captured through its xingxiang (outer form of the object). As $\mathrm{Gu}$ was mostly a painter of figures, he probably meant to capture typicality through visible physical features. The roots of his understanding can still be found in the symbols of xiang (image) mentioned in Zhouyi (The Zhou Book of Change). It is very much likely that $\mathrm{Gu}$ realized the importance of the spirit, and to him, the outer form was no other than a means to capture and express the spirit. "That the art of painting required unification of dualities, as does the cosmic creative process, was already acknowledged by the earliest painter to write on his art." [7]

Further development concerning spirit conveyance was made by Xie He (479-502) who proposed six important laws that specified what painters should observe in painting, and these laws later became a popular set of quality assessment criteria for Chinese paintings (two of which were translated and introduced to Westerners by Kakuzo Okakura in 1903). The first and most renowned is qiyun shengdong, which means "the life-movement of the spirit through the rhythm of things" in Kakuzo's words. James Cahill translated it as "engender a sense of movement through spirit consonance", in contrast to Wen Fong's version of "vitality, harmonious manner and aliveness". Up till today, its translations and changes in meaning over the history of Chinese art criticism are still quite extensively discussed by many scholars in China and the West, including Lin [17] and Sze [18].

"It is then extended to mean the life-spirit of the Universe, a kind of subtle electricity-like fluid pervading all things. But this all-pervading $q i$ has its modalities; it is not evenly distributed everywhere but flows about in ever-changing streams and eddies, here deep, there shallow, here concentrated, there dispersed. Inanimate and animate things all have their share of $q i$, but in varying degrees of intensity." [4]

As shen most often collocates with qi to mean shenqi (spiritual quality) and both indicate the vitally dynamic quality of things, it is no wonder that here shen (the spirit) is explained by way of $q i$ to illuminate its subtlety. Till then, spiritual resemblance through imagination in painting was widely acknowledged in comparison with formal likeness through imitation. When Xie He commented on other painters' works, he said, "The mechanical likeness in form may lead to the loss of essence, while detaching of the form brings artful extrication of the opulent appearance, so to speak, delicate experience." [19] Today, we still see his legacy well inherited, as Qi Baishi (1864-1957), a famous modern Chinese painter, once said, "The ingenuity of painting rests on balancing likeness and unlikeness for too much similarity shows kitsch while too little stands for cheating." [20] The shrimps painted by Qi are the very lifelike works that seem both artistically real and unreal.

\subsection{The Third Stage: Painting as a Cure Through Intent-expression}

To capture shen, one is required to have a well-based personal understanding of the painting in question as well as its function. However, it is also justifiable to say that chuanshen (conveying the spirit) theory mainly prevailed in figure painting; and probably because painters found themselves confined to this particular field and incapable of making any breakthrough until later in the Song dynasty (960-1279) they turned their eyes to landscape painting that promised further theoretical development and greater possibilities of self-expression. Another major social-historical factor possibly contributing to painters' regarding painting as a cure was that "for many literati who were resistant to the reign of Yuan emperors (1271-1368) but unable to revolt, the only way to alleviate their indignation and pain was to bury themselves in poetry, calligraphy and painting." [3] As for painting, to achieve qiyun shengdong (vital resonance and life movement), an artist at least should paint nature or things as they are by themselves. Nevertheless, when the highest aim of the painter has become to symbolize his spiritual life and deploy Tao, or to blend completely with one's environment, it needs more stirring profundity to establish a spiritual connection between the object, the painter and the viewer so as to effect catharsis on them. Landscape 
painting in particular "became the emblem of moral integrity, of one's harmonious integration with nature, in which the Chinese literati found their ideal way to coexist with nature." [21] This precisely exemplifies the very influence of Zhuangzi's ideas and concepts. As many scholars agree that the greatest impact on Chinese landscape painting and its ideas was made by classical Taoist philosophy especially by Zhuangzi, Li Zehou [22] holds that it is aesthetic in its essence and says Zhuangzi.

urged people to take an aesthetic, contemplative attitude towards life as a whole: discount gain and loss, success and failure, right and wrong, merit and demerit; forget the self and things, subject and object, the self and others, and thereby let the self and the whole universe blend into one.

What Zhuangzi upheld here is often found quite inspiring by many people (including painters of all ages) in that it shows a possibility for them to live their lives aesthetically by embracing a contemplative and holistic vision of the world. His ideology was also adopted by Su Shi (1037-1101) througout his life time, who, together with another painter and poet Ouyang Xiu (1007-1072) of the Song dynasty, was said to have established the Intent-Expression theory for Chinese painters. As Moeller [23] noticed, a Taoist understanding of the art is more concerned with the concept of artisanship and the process of creation of the piece of art rather than with the concept of beauty and the piece of art itself (and in the case of landscape painting--with nature itself rather than with the depiction of nature or its imitation). Among others, the best model for painters to exemplify the process and convey the movement of life has been bamboo. A painter has to convey not its form, but rather the moving impulse for its growth. He has to comprehend and represent in the painting the whole process of bamboo's growing from its roots to the tips of its leaves, as it stated by Su Shi, When bamboo first comes into being, it is only an inch-long shoot, but the joints and leaves are all in it. It develops from cicada chrysalises and snake scales to swards drawn out eighty feet, because this development was immanent in it. Now when painters do it joint by joint and add to it leaf by leaf, will this be bamboo? Thus, in painting bamboo one must first have the perfected bamboo in mind. [24]

It indicates the concept of $y i$ (intent or idea) and the associated strategy of "yizaibixian" (that the intent precedes the brush), as adopted by Zheng Banqiao (1693-1765), a Qing official and painter who claimed that he couldn't live without bamboo, who said, "Lying in the study of government office to hear the rustling of bamboo... every small thing about people's livelihood affects we officials' feelings." [11] Bamboo in his painting is an expression of subjective emotion and product of interaction between emotion and scenery. Gao Jianping [25] raises the question, "What was the painter really looking at when he took up the brush and contemplated intently? Was he looking at bamboo, or at silk or paper?" His answer is that he was looking at the silk or paper, because at the moment of painting, "there was actually no bamboo present in front of him. It was by virtue of his spiritual concentration that he saw in his mind the image of bamboo", and this image seemed to him truer than the image of the real bamboo seen before, because it "involved the realization of a more profound communication with the object".

An intent or idea was formed in the painter's mind as the result of knowing or realizing "why it is so or why a thing is as it is". [25] Such a realization comes only after long contemplation of nature--bamboo, trees, mountains at different moments of life, weather, and time. One typical example is Guo Xi's observation of mountains and trees at different weathers:

In spring, the clouds and mist drifting through mountains make people imbued with vitality; in summer, the flourishing trees provide perfect shade for passengers; in autumn, the clear and clean mountains with fallen leaves in gay profusion are immersed in a solemn atmosphere, and in winter the mountains turn dark and gloomy, making people lonesome as well. [11]

Those various faces of mountains and trees when identified as the object of painting, according to Zong Bing (375-443), are better recreated by a painter who can feel, absorb and seize the natural principle as he moves his eyes accordingly with a responsive heart. He said, "a landscape painter can express its philosophical principle of Tao through the outer form of scenery, and Tao can thus be understood through a landscape painting."[10] The purpose of such a painting is to provide the same mystical spiritual experience for viewers that they would have had in the same actual mountains. Munkata interpreted Zong's theory of landscape painting as an application of his karmic theory about sacred mountains to the paintings of them. In his words, Zong's "perception of and response to the spirit" is a "visibly mystical manifestation of the spiritual karmic interactions behind all occurrences in the universe." [26]

That is to say, not only is there a procedural unification of the painter and painting, but also there is a behavioral spontaneity and integration of the painter and the world, in which the painted and the painting would inevitably become part of the painter's spiritual life. A Tang dynasty poet and official $\mathrm{Fu}$ Zai talked about the painting of his contemporary Zhang Zao.

When we contemplate Master Chang's (Zhang) art, it is not painting, it is the very Tao itself. Whenever he was engaged in painting, one already knew that he had left mere skill far behind. His ideas reach into the dark mysteries of things, and for him, things lay not in the physical sense, but in the spiritual part of his mind. And thus he was able to grasp them in his heart, and make his hand accord with it. [7]

It is very difficult to discern the appearance and disappearance of the boundaries between the painter and the world in this process, since they are simultaneously united and not-united. [1] This sense of the inseparability has often been described by Western and Chinese interpreters as "the unity of (or harmony, intimacy between) human and nature", or even as "the act of reverence for nature", and contrasted with the Western model of "the separateness of human and nature" in the comparative analysis of Chinese and Western painting and their aesthetics. But to discuss a Taoist model in this contrastive Western-Chinese formula is "an implicit 
Eurocentric tendency to view (even by naming) 'nature' and 'the human' as two separate realms," [1] because there is no clear division between them in Taoist classical philosophy nor in Chinese painting and its aesthetics.

There is harmonization of the painter with things painted in his producing of the artwork, and it is particularly so for those who left the imperial court and those who repulsed bureaucracy so as to refuse to serve the government. Zhao Mengfu (1254-1322), a great master of Taoist philosophy and renowned painter, regained his inner peace and reached his highest achievement in calligraphy and painting after he disappointedly resigned from the imperial court. Another similarly famous painter Huang Gongwang (1269-1354) was a Taoist priest who had been disillusioned and become a wanderer between mountains and river before he created "Dwelling in the Fuchun Mountains", one of the best ancient Chinese paintings in history. A more typical example is Ni Zan (1301-1374) who, after many years of miserable life, joined Quanzhen Taoism and started to find sustenance and cure through landscape painting. As for painting-lovers, they manage to perceive the excellence of the artist and to experience the subtlety of the imagery and idealized world that depicts a lifestyle different from their own, thus achieving similar catharsis and peace. Many accomplished Taoist priests at that time were great painters and painting-lovers: Taoist Master Zhang Zongyan (1244-1292) with his sons and grandsons, Fang Congyi (1302-1393), just to name a few. Among others, intent-expression with its increasing development in landscape painting and ink wash painting gained ever more popularity in Ming and Qing dynasties. For that, one finds an explanation from what Zhuangzi said about harmony that Chinese literati have always been pursuing, "Tao looks dim and obscure and sounds silent and tranquil. Yet, there is a glimmer in the dim obscurity and there is a harmony;" [9] it seems both the painter and the viewer tried to find harmony in painting with their Taoist life philosophy as a cure to pacify themselves.

Since then, painting with a subjective intent has been playing an important role with its spiritually healing power, not only in the life of many talented landscape painters and some unappreciated literati, but also in the life of painting-lovers who would have consonance and resonance with everything involved in artworks. "Mollusks in misery would make the best pearls. Birds startled would fly up high into the clouds and over the snow-clad peak of mountains. Because they are vigorously stirred by their sufferings, they could fly farther and higher." [27] The painter, stirred or peaceful, forgets himself or his previous experience and simply reacts to the movement of nature like an echo. As nature in ancient Chinese painting has never been viewed as something in opposition to human but from a macrocosmic perspective of the unity of things, of which the human point of view is an integral part, this movement of painting brings the painter and the viewer to the mysterious principles or common source of all beings. This over-introspective inclination in Chinese painting tradition is not without disapproval, but the most important fact is that these painters and painting-lovers created their own space where they could find beauty and safety, their "Weltiinneraum" where they could heal themselves with the power of art and nature.

\section{Conclusion}

Painting is the greatest method for representing the world in the process of transformation and interaction, for capturing the essential beauty of landscape's dynamic forms, the eternal activity of creation, the succession of day and night and of the seasons. [28] Chinese painters and painting critics obviously managed to do that in their own way. With the elementary development based on plain imitation and further refinement stimulated by artistic imagination, these artists ultimately found the Taoist philosophy inspiringly applicable to fulfill a function with personal spiritual satisfaction. Among others, literati painters of landscape painting were particularly benefited in that Laozi and Zhuangzi presented a contemplative attitude towards life as a whole, making it possible to let the self and the whole universe blend into one, the very fact which paved the way for their inner peace. This spiritual momentum is powerful enough to walk them through all ups and downs in life, and contagious enough to pacify painting viewers. With natural affinity for appreciators, artistic works affect them during the appreciation process and generate resonance from pleasing their eyes, their ears, and ultimately their souls.

Form likeness, spiritual resemblance, and intent-expression are among the most frequently used terms in Chinese painting theory and traditional Chinese philosophy as well. In contrast, concepts of presence/absence and losing/gaining of one's self seem very important for Westerners who understand one's identity as definite and substantial, but they are less so for ancient Chinese painters who were more concerned with the question of emptying one's heart and mind in order to comprehend the world in its wholeness. This is because Chinese painters tend to look into the world and the myriad of things from the perspective of oneness or great harmony. Despite the basis of a functional subject-object relation applied above to the division of phases in Chinese painting theory development, which is only for the convenience of discussion, the tendency to describe the unity between the painter and things depicted by Western terms of subject/object relations is somehow problematic since "these terms are often used in the Western translations of Chinese texts on painting and the related studies" and "they seem misleading and not useful in the context of Chinese painting". [1]

With its extreme purity and ethereality, modern men often find an intent-expression painting beyond comprehension, because it hardly reflects the painter's world then and there. But we need to know that literati painters tried to built an idealized world that couldn't be found anywhere in reality, that builds an imagined space to keep themselves detached and recluse to guard their spiritual independence and pursuit, albeit its utopian nature. As visual art, painting could somehow cast aside specific shape of the object and together with it the concrete physical world, which to some extent 
makes the transition from pursuit of formal likeness to that of spiritual resemblance understandable. Ancient Chinese painters and critics did not linger long at the crossroad. They preferred a path not taken by European oil painters in their pursuit of the spirit, developing the art of painting into something philosophically able to cure their pains and miseries. It could inspire contemporary painters who are trying to forget the form and capture the spirit in abstract painting. And this historic divergence becomes increasingly substantial and difficult for East-West cultural translation and communication as time goes by, but it gratifyingly keeps manufacturing spiritual panacea for painters and painting lovers as well.

\section{References}

[1] Poskaite, Loreta. The Embodiment of Zhuangzi's Ecological Wisdom in Chinese Literati Painting (wenrenhua) and Its Aesthetics. Asian Studies V (XXI), 2017. PP. 221-239.

[2] Gombrich, E. H. The Story of Art. London: Phaidon Press. 1989.

[3] Yang, Shenyuan. On the Two Major Schools of Ancient Chinese Painting Theories. Nanjing Art Institute Journal. 1986. 2: 51-58.

[4] Acker, William Reynolds B., transl. Some T'ang and pre-T'ang texts on Chinese Painting. Leiden: E. J. Brill. 1954.

[5] Gao, Jianping. The Wheel of Fortune vs. the Mustard Seed: A Comparative Study of European and Chinese Painting. Diogenes. 2013. 59 (1-2): 101-117.

[6] The Zhou Book of Change. Translated into English by $\mathrm{Fu}$ Huisheng; Library of Chinese Classics, Chinese-English. Changsha: Hunan People's Publishing House. 2008.

[7] Bush, Susan \& Shih Hsio-yen, eds. And comps. Early Chinese Texts on Painting. Cambridge, Massachusetts, London: Harvard University Press. 1985.

[8] Yu, Jianhua, ed. Selected Readings on Chinese Painting Theories. Beijing: People's Fine Art Publishing House. 2010.

[9] Zhuangzi. Zhuangzi. Translated into English by Wang Rongpei; Library of Chinese Classics, Chinese-English. Changsha: Hunan People's Publishing House, Beijing: Foreign Languages Press. 1999.

[10] Zhang Yanyuan (of the Tang Dynasty), ed. A Review of Past Famous Paintings. Beijing: People's Fine Arts Publishing House. 1964.

[11] Zhu, Zhirong. Philosophy of Chinese Art. Shanghai: East China Normal University Press. 2012.

[12] Tang, Yimeng \& Daniela Zhang-Czirakova. Theoretical
Sources for Abstract Painting in the Ancient Chinese Art Theory Before the Tang Dynasty. Journal of Sino-Western Communication, Volume 7, Issue 1. 2015.

[13] Gao You (of the Han Dynasty), ed. Huai Nan zi (Writings of Prince Huainan) In The Complete Works of Philosophers and Scholars: Volume 16. Beijing: Zhonghua Book Company. 1954.

[14] Sullivan, Michael. The Arts of China. London: University of Califoria Press. 1977.

[15] Liu Xie (of the Liang Dynasty). The Literary Mind and the Carving of Dragons, Annotated by Fan Wenlan. Beijing: People's Literature Publishing House. 1958.

[16] Hu, Wentao \& Luo, Qin, ed. Collected Works by Wang Changling with Annotations. Chengdu: Bashu Press. 2000.

[17] Lin, Yutang, transl. The Chinese Theory of Art. London: Heineman. 1967.

[18] Sze, Mai-mai. The Tao of Painting: A Study of the Ritual Disposition of Chinese Painting. Bollingen Series XLIX, New York: Pantheon Books. 1956.

[19] Shen, Zicheng, ed. On Ancient Paintings In The Collected Past Reviews on Famous Paintings. Shanghai: World Book Company, 1984.

[20] Qi Baishi. "Comments on Painting with $\mathrm{Hu}$ Peiheng and Others", In Talks on Painting of Qi Baishi, Zhengzhou: Henan People's Publishing House. 1984.

[21] Chen, Zhidong. Chinese Literati's Consciousness in Painting and Calligraphy. Guangxi Normal University Press. 2017.

[22] Li, Zehou. "Zhuangzi and Chan Buddhism." In Contemporary Chinese Aesthetics, edited by Zhu Liyuan \& Gene Blocker, 143-178. New York et al.: Peter Lang. 1995.

[23] Moeller, Hans-Georg. Daoism Explained: From the Dream of Butterfly to the Fishnet Allegory. Chicago and La Salle, Illinois: Open Court. 2004.

[24] Bush, Susan. The Chinese Literati on Painting. Su Shih (1037-1101) to Tung Ch'i-Ch'ang (1555-1636). 1971. Cambridge: Harvard University Press.

[25] Gao, Jianping. "The Expressive Act in Chinese Art: From Calligraphy to Painting." Acta Universitatis Upsaliensis 7. Uppsala: Uppsala University. 1996.

[26] Munkata, Kyioshiko. "Concepts of Lei and Kan-lei in Early Chinese Art Theory" In Bush, S. \& Murck, C., ed. Theories of Arts in China. Princeton \& New York: Princeton University Press. 1983.

[27] Liu Zhou (of the Northern Qi Dynasty). Liuzi, annotated by Yuan Xiaozheng. Beijing: Zhonghua Book Company. 1985.

[28] Strassberg, Richard E. Transl. And comp. Englishtening Remarks on Painting by Shih-T'ao. Pacific Asia Museum Monographs, No. 1 Pacific Asia Musuem. 1989. 